\title{
Paciencia impaciente. La comprensión teológico-política del tiempo en Rosenzweig y Levinas
}

Diego Fonti

Universidad Católica de Córdoba

Argentina

Para citar este artículo: Fonti, Diego. «Paciencia impaciente. La comprensión teológico-política del tiempo en Rosenzweig y Levinas».

Franciscanum 169, Vol. LX (2018): 109-142.

\section{Resumen}

El objetivo de este trabajo es identificar el sentido que lo teológico y lo político asumen en Rosenzweig y Levinas. Para ambos son modelos de reflexión y práctica posteriores al encuentro fundante de la relación entre el sujeto y la alteridad. La filosofía que tematiza esa relación encuentra en el lenguaje teológico las nociones con que expresarse. A nivel práctico, la política será influida directamente por la concepción filosófico-teológica que se asuma. Surge la paradojal imposibilidad y necesidad de una teología política. Y la experiencia de la impaciencia y paciencia del tiempo se muestra como lugar paradigmático de aparición de lo teológico-político en ambos autores.

\footnotetext{
Licenciado en Filosofía (Universidad Nacional de Córdoba, Argentina); Doctor en Filosofía (Albert-Ludwigs Universität Freiburg, Alemania). Investigador de CONICET (Comisión Nacional de Investigaciones Científicas y Técnicas). Profesor titular de Ética de la Universidad Católica de Córdoba y de la Maestría en Filosofía, Religión y Cultura Contemporáneas de la misma universidad. Director del equipo de investigación «Interculturalidad y Derechos Humanos en América Latina», en la Unidad Asociada al Conicet, Área de Ciencias Sociales y Humanidades, Universidad Católica de Córdoba, Argentina. Contacto: diego.fonti@ucc.edu.ar,diegofonti@gmail.com.
} 


\section{Palabras clave}

Rosenzweig, Levinas, teología política, tiempo, paciencia.

\section{Impatient Patience. The Theological-Political Understanding of Time in Rosenzweig and Levinas}

\section{Abstract}

The purpose of this paper is to identify the meaning that theology and politics take on in Rosenzweig and Levinas. For both authors they deal with ways of reflection and practice posterior to the founding relationship of the subject and the other. The philosophy that deals with this relationship finds in the theological language the concepts with which it can be expressed, without becoming theology because of that. And at the practical level, politics will be directly influenced by the philosophical-theological understanding it assumes. From both philosophies it is deduced the paradoxical impossibility and necessity of a political theology. The experience of patience and impatience of time appears as central for understanding the emergence of the theological-political in both authors.

\section{Keywords}

Rosenzweig, Levinas, political theology, time, patience.

\section{Introducción}

Los grandes pensadores siempre han significado, al mismo tiempo, la presentación de ideas o experiencias de un modo creativo y una renovación del lenguaje capaz de exponer esas ideas y 
experiencias. Han visto y dicho algo que hasta ese momento no había accedido suficientemente a la inteligibilidad y el lenguaje. En Rosenzweig y Levinas, esa renovación sucede a nivel de una comprensión de la experiencia ético-religiosa, en tanto irrupción del Otro ante una subjetividad que, mediante esa recepción de la alteridad, se reconoce responsable en una relación que rompe toda totalización, o sea, que niega todo englobamiento que pudiera hacer su propia conciencia del Otro que se manifiesta llamándole. Más allá de las diferencias metodológicas e históricas, ambos ponen en escena un modo de relación no totalizador con el Otro, con fuertes resonancias del pensamiento y experiencia judíos. El uso renovado de categorías religiosas como creación, mesianismo y redención, no tiene una voluntad apologética ni misional, sino la de recurrir a un lenguaje que pueda plasmar mejor la experiencia relacional, renovando al mismo tiempo tanto la filosofía como el ámbito de proveniencia de esos términos. En términos de Rosenzweig: solo con estas «categorías» pueden comprenderse los elementos irreductibles -Dios, ser humano, mundo- en una relación dialógica y no reductiva. Ambos filósofos no se proponen una teología sino una filosofía. Esto es importante, pues la adjetivación de «teológicopolítica» a una determinada comprensión, en este caso del tiempo, no debe cometer el error de presentar como teológico-políticos a los autores de referencia. Los textos y la estructura fundamental de pensamiento de Rosenzweig y Levinas llevan a pensar en un claro distanciamiento de algunas nociones de influencia schmittiana, como por ejemplo la separación de los elementos Dios-hombre-mundo en Rosenzweig y su crítica a los modelos que subordinan el valor y la acción de los seres humanos individuales a una polis que los fagocita, o la anterioridad de una relación ética a la praxis política en el caso de Levinas. Son filosofías que no admiten que lo político sea objeto primero y último de la relación interhumana, y que por otra parte entienden la relación con lo divino no como legitimación de la Realpolitik, sino como parámetro de juicio de y trascendente a toda realización concreta. Pero son sus textos también los que muestran 
que algunas nociones en juego, como la experiencia de impaciencia de los «tiranos del Reino» en Rosenzweig y la paciencia del tiempo en Levinas, permiten reubicar teológico-políticamente sus filosofías. Este trabajo es un intento de formular dicha reubicación.

La tensión de una paciencia impaciente expresa el movimiento de la temporalización de la subjetividad puesto en escena por el monoteísmo. En tanto que «experiencia pre-filosófica» monoteísta, implica un abordaje filosófico de una comprensión teológica de la temporalidad con fuerte incidencia en la praxis pública. No es una comprensión teórica con efectos prácticos, sino un despliegue pragmático desde los compromisos portados por dicha comprensión, que a su vez profundizan la comprensión y radicalizan la praxis ${ }^{1}$. El objetivo de este trabajo es, ante todo, identificar el sentido que lo teológico y lo político asumen en Rosenzweig y Levinas, en tanto modos de reflexión y práctica segundas, posteriores al encuentro fundante de la relación entre el sujeto y la alteridad. Pero la filosofía que tematiza esa relación encuentra en el lenguaje teológico las nociones con que expresarse, sin convertirse por ello en teología. A nivel práctico, la política será influida directamente por la concepción filosófico-teológica que se asuma. Estos resultados se recapitulan mostrando que de ambas filosofías se deduce la paradojal imposibilidad y necesidad de una teología política. A continuación se aborda el tema de la temporalidad, como lugar paradigmático de aparición de lo teológico-político en Rosenzweig y Levinas. La reflexión de Rosenzweig sobre la tiranía y la tentación de quienes sienten la necesidad de adelantar impacientemente la llegada del Reino, y la exposición levinasiana de la paciencia como clave para el mesianismo de la «pequeña bondad», establecen una tensión fecunda para comprender la temporalidad de modo teológico-político.

1 Por ello no se trata de la «theologia naturalis», exposición racional-teorética de las cosas vinculadas con lo teológico, ni de la «theologia civilis» y sus sucedáneos modernos, sino de una hermenéutica situada en la praxis y comprensión de lo que sucede en los compromisos con el mundo teológicamente motivados. Cf. Ernst Feil, Religio. Vierter Band: Die Geschichte eines neuzeitlichen Grundbegriffs im 18. Und frühen 19. Jahrhunderts (Göttingen: Vandenhoeck \& Ruprecht, 2012), 70 y 127. 


\section{Rosenzweig: la nueva filosofía como «Antiguo Testamento» de teología y política}

La obra general de Rosenzweig, sobre todo su Estrella de la Redención, pretende elaborar un sistema filosófico desde lo que él denomina «nueva filosofía» ${ }^{2}$, «nuevo pensamiento» 0 «pensamiento hablante» ${ }^{3}$. Su rasgo esencial es «tomar en serio» al lenguaje y al tiempo, en tanto experiencias siempre dirigidas hacia otro y dependientes de este ${ }^{4}$. Su intención es separarse del idealismo imperante en la filosofía desde el mundo griego y hasta el idealismo alemán, así como mostrar que los elementos irreductibles del filosofar, Dios, el ser humano y el mundo, pueden ser vistos de un modo diverso al clásico gracias a las «categorías» de análisis provenientes del monoteísmo bíblico. Si el gran logro de la filosofía es resistir a la reducción -intentada una y otra vez por los filósofos- de todos los elementos fundamentales a uno de ellos, la propuesta de Rosenzweig es recuperar la relación entre ellos, una relación no subsumible bajo una totalidad, sino que implica la presencia constante y dialógica de la multiplicidad. Esta relación tiene una doble condición de posibilidad: filosóficamente, el análisis de los elementos en su persistencia y multiplicidad permite evitar todo riesgo totalizador y, teológicamente, es decir, abordando los elementos en el modo de relación que el monoteísmo propone, se expone el vínculo entre los mismos y el modo en que esta relación se relaciona con el tiempo y su sentido.

Rosenzweig no intenta elaborar una disciplina filosófica particular -por caso, la filosofía de la religión- sino hacer una filosofía con impacto en diversas áreas, incluida la que analiza el fenómeno religioso. Su uso filosófico de conceptos y experiencias teológicas está directamente vinculado con la pretendida elaboración de una filosofía nueva. Esa filosofía es practicada por pensadores que pueden ubicarse desde

Franz Rosenzweig, La Estrella de la Redención (Salamanca: Sígueme, 1997), 148.

Franz Rosenzweig, El nuevo pensamiento (Madrid: Visor, 1989), 63.

Franz Rosenzweig, El nuevo pensamiento, 63. 
la perspectiva de un "acontecimiento» teológico, o sea, en la cual creación, revelación y redención sean vividas y pensadas. Esa filosofía debe ser practicada por un pensamiento teológico-filosófico, y este pensamiento es «antiguo testamento, por así decir, de la teología» ${ }^{5}$. Este modo de pensamiento filosófico es afectado por nociones teológicas, pero se vuelve sobre teología y filosofía, renovándolas. Esta filosofía no es organon o prote episteme desde la cual deducir luego verdades o poner al servicio de la teología revelada para servirle de soporte y estructura lógica, sino un modo primero de exposición de las realidades en juego en todo pensamiento, que tienden a relacionarse y encuentran en las nociones teológicas mismas el espacio para esa relación. Este modo de filosofar teologizante es también, según Rosenzweig, el que permite dar cuenta de un modo de praxis que hace honor a la multiplicidad en relación, que respeta a cada elemento en su realidad sin eliminar su interrelación.

El ser de Dios -allende toda física-, el sentido del mundo -allende todo ordenamiento lógico-, y la realidad del ser humano -allende toda subsunción a un ethos- son las tres protorealidades que Rosenzweig analiza en la primera parte de su Estrella. Ya este triple análisis de metafísica, metalógica y metaética encuentra como punto de partida el lenguaje, puesto que hay protopalabras o palabras originarias vinculadas con los tres elementos irreductibles: el sí, el no y el así ${ }^{6}$. Cada una de ellas entabla una relación distinta según se trate de Dios, del mundo o del ser humano. Pero estas protopalabras no son suficientes para comprender al diálogo realmente dado. Son condiciones de posibilidad teóricas, pero no tienen la vitalidad y realidad de una comunicación acontecida. Por eso, el punto de partida de esta nueva filosofía es el lenguaje realmente hablado, donde la comunicación realmente ha acaecido. El vínculo pasado de la creación, el presente de la revelación y el futuro de la redención no son nociones o conceptos previos sino realidades existentes y en

5 Franz Rosenzweig, La Estrella de la Redención, 150.

6 Franz Rosenzweig, La Estrella de la Redención, 67, 71, 84, 106. 
relación ${ }^{7}$. Así como bajo cada palabra están escondidas las palabras originarias, también los elementos originales irreductibles están supuestos en cada relación ${ }^{8}$. Las palabras originales se dan en el lenguaje viviente y los elementos irreductibles se dan efectivamente de modo relacional. El trabajo filosófico consiste en desentrañar esta relación, y para ello Rosenzweig afirma necesitar de términos de proveniencia teológica.

Pero Rosenzweig no se propone una renovación de la religión, sino encontrar su estructura fundamental anterior a toda constitución institucional o doctrinaria. Su apelación a la teología no es apologética ni institucional, ya que las religiones -histórica e institucionalmente hablando- han sido para él una caricatura de la relación religiosa fundamental ${ }^{9}$. Casper anota al respecto que en una relación así deformada, muchas otras realidades pueden endiosarse, y por eso para Rosenzweig judaísmo y cristianismo no fueron en su origen religiones, sino modos de darse el vínculo del ser humano con Dios, con el mundo y los demás hombres ${ }^{10}$. A diferencia de las religiones paganas y del islam, que fueron creadas explícitamente como religiones, judaísmo y cristianismo no lo fueron, aunque en su historia hayan devenido instituciones en sentido específico de una estructura relacional e institucional establecida. Por eso late en ambos un impulso que puede liberarles de ese apresamiento a la religión instituida, y volver al «campo libre de la realidad» ${ }^{11}$.

El trabajo del «nuevo filósofo»y del «nuevo teólogo» tiene la fuerza, precisamente en vistas de la relación con el Dios vivo, de «hacer el mundo nuevamente irreligioso» ${ }^{12}$. Una teología como

\footnotetext{
Franz Rosenzweig, La Estrella de la Redención, 150.

Franz Rosenzweig, La Estrella de la Redención, 151.

Franz Rosenzweig, Gesammelte Schriften 3, Zweistromland. Kleinere Schriften zu Glauben und Denken (Den Haag: Martinus Nijhoff, 1984), 493, 497.

10 Bernhard Casper, Das Dialogische Denken. Franz Rosenzweig, Ferdinand Ebner und Martin Buber (Freiburg/München: Alber, 2002), 193.

11 Franz Rosenzweig, El nuevo pensamiento, 69-70.

12 Franz Rosenzweig, El nuevo pensamiento, 70; Franz Rosenzweig, Briefe und Tagebücher 1900-1918, Gesammelte Schriften 1, Band 1 (Den Haag: Martinus Nijhoff, 1979), 768.
} 
apologética argumentativa de verdades creídas por fe pierde sentido. Surge una teología entendida como el espacio en que a partir de la nueva filosofía se construye un puente entre creación y revelación, y entre revelación y redención. Esta relación no se entiende como contenidos argumentales sino como un "acontecimiento» que necesita un «teólogo vivencial»» ${ }^{13}$. Así, el proceso seculatorio resultaría del mismo aporte bíblico, porque este «desdiviniza» el mundo mundanizándolo, y poniendo todo el peso de la libertad en los sujetos. Saeculum, o la inscripción en la temporalidad vivida del sentido de la misma, significa una doble relación: por un lado, las responsabilidades en juego no pueden proyectarse a un trasmundo o desligarse de sus responsables; al mismo tiempo, la experiencia judeocristiana vincula lo pasado, lo presente y lo porvenir con creación, revelación y redención, que aportan un plus de responsabilidad a las acciones. Para Rosenzweig es con la revelación monoteísta que se rompe definitivamente la «vieja» filosofía, porque muestra un modo de comunicación demandante, exigente, que requiere que a cada momento haya una transformación y una respuesta al modo de los amantes ${ }^{14}$. A cada palabra le corresponde una contra-palabra, a cada demanda una respuesta. La contraposición o mutua exclusión entre mandamiento y libertad, y entre inmanencia y trascendencia, se rompen en la comunicación efectiva, mostrada por antonomasia en la revelación ${ }^{15}$. Se manifiesta un mandato, que al comandar amor no niega la libertad, sino que la presupone. Este mandato proviene de fuera, es trascendente, pero se revela interior y donante de identidad subjetiva, generando un «sí mismo» distinto del héroe soberano.

Antes que, de las potencias del individuo, la filosofía que Rosenzweig propone parte de aquello que el individuo no puede manejar, lo otro del individuo, como aparece en el lenguaje: no porque este sea «deficiente» para expresar la totalidad de lo dado y

\footnotetext{
13 Franz Rosenzweig, La Estrella de la Redención, 150.

14 Franz Rosenzweig, La Estrella de la Redención, 204.

15 Franz Rosenzweig, La Estrella de la Redención, 246, 266
} 
sus relaciones, ni mucho menos porque la «deficiencia» sea la del sujeto que requiere de una mediación para expresarse, sino porque el lenguaje muestra «que necesitamos tiempo». «Necesitar tiempo significa: no poder anticipar nada, tener que esperarlo todo, depender de otros en lo propio» ${ }^{16}$. El «pensador hablante» está ligado al tiempo porque su pensamiento nace en la comunicación, no en el solipsismo. Y la comunicación requiere de otros y de tiempo. Esta doble necesidad es ubicada por Rosenzweig en el marco teológico, haciendo así de lo teológico un marco de comprensión para lo político. Entonces todo pensamiento filosófico ha sido, de un modo u otro, una concepción teológico-política. Toda perspectiva filosófica ha proporcionado una idea coherente consigo misma sobre la relación con lo divino y sobre las consecuencias que dicha noción filosófica y teológica ha tenido en el trato interhumano. No solo es improcedente pensar que es posible una filosofía de la praxis sin injerencias teológicas, sino además, y sorprendentemente, una relación teológico-política adecuada es la que puede permitir desenmascarar como idolátrico lo que muchas configuraciones religiosas han instituido. En este sentido puede también hacer al mundo realmente irreligioso devolviéndole a la experiencia relacional originaria. Finalmente, puede exponer un modelo de relación en que el ser humano permanezca humano, el mundo mundano y Dios divino, sin perder la relación mutua.

¿Cómo se inscribe la subjetividad individual en esta relación entre elementos fundamentales y en su dependencia simultánea de alteridad y temporalidad? Una respuesta posible es la experiencia de la temporalidad subjetiva. Experiencias como la muerte, al inicio de la Estrella, y la posibilidad del canto coral común al final, no son solo «existenciales» que muestran el despliegue de la existencia monoteísta y su sentido en vistas de acontecimientos esenciales. Son además los lugares filosófico-teológicos en los cuales exponer el paso del hombre metaético -individuo aislado previo a toda donación de sentido, cuya máxima expresión se da en la figura del 
héroe griego- a la del sujeto en comunicación efectiva. El Estado antiguo era «el Todo del que sale una corriente unitaria de energía que pasa a través de sus miembros» ${ }^{17}$. En esta totalidad aparece la máxima individualidad y la máxima pérdida de la singularidad. El individuo no se pierde para encontrarse, sino "para edificar la comunidad. Él mismo desaparece». En la estructura que Rosenzweig identifica tanto en el mundo clásico griego como en la Ecumene de Augusto, la comunidad es «algo último, más allá de la cual le está vedado mirar» ${ }^{18}$. La experiencia del individuo humano, el «sí mismo», en este contexto clásico greco-romano, se manifiesta en su máxima expresión en la figura del héroe: en el momento en que muere y deja de ser es cuando su individualidad alcanza su máxima expresión. Por eso la «personalidad tiene que dejarse des-personalizar» en el momento de máxima soledad, allí tiene su mayor fuerza como carácter, ethos ${ }^{19}$. Cuanto menos sí mismo es el héroe, más fuerte como carácter se manifiesta y su heroicidad alcanza su máxima expresión. Estas dos características de la relación política clásica, totalidad estatal y aniquilamiento de la individualidad en pos de la totalidad, subordinan el tiempo de los individuos a la vida del Estado. Corresponde a la temporalidad que instaura el monoteísmo romper con este modo de temporalidad política, inscribiendo la temporalidad subjetiva en otro orden que al mismo tiempo trasciende la temporalidad y la radicaliza; que al mismo tiempo insubordina al individuo y mantiene su dependencia de la alteridad; que al mismo tiempo, en suma, vincula secularización política y trascendencia teológica sin subsumirlas una a otra.

Ver la realidad desde la filosofía de Rosenzweig significa asumir una «teoría mesiánica del conocimiento», la cual «valora las verdades según el precio de su confirmación y según el vínculo que crean entre los hombres, no puede sin embargo llevar más allá de las dos esperas

\footnotetext{
17 Franz Rosenzweig, La Estrella de la Redención, 96.

18 Franz Rosenzweig, La Estrella de la Redención, 97.

19 Franz Rosenzweig, La Estrella de la Redención, 113.
} 
del mesías, irreconciliables siempre: la del que viene y la del que vuelve ${ }^{20}$. No se trata de una afirmación menor, pues el mesianismo, entendido estrictamente al modo de Rosenzweig, será la «piedra de toque» para juzgar las construcciones subjetivas y políticas en clave monoteísta. En sus dos caras, la judía y la cristiana, el mesianismo instala una relación con el futuro y la actividad presente que tiene consecuencias públicas de peso. En ambas perspectivas, el mesianismo significa el modo en que se da el futuro como tensión hacia una realización plena de la sociabilidad humana y de todo lo creado, es decir, la redención. A nivel subjetivo las implicancias son significativas, en tanto la temporalidad subjetiva asumirá compromisos diversos según sea su relación con ese futuro mesiánico y cada tipo de compromiso significará un modo distinto de ejercicio político.

\section{Levinas: la anterioridad de la ética a la teología y a la política}

En un gesto que acerca claramente su filosofía a la de Rosenzweig, más allá de las alusiones explícitas e incluso de modo más fundamental que su común crítica a la totalidad, Levinas cuestiona el modelo de pensamiento metafísico-contemplativo occidental. Lo que caracteriza a este pensamiento es el solipsismo, la soberanía del pensante y la atemporalidad de lo pensado, en síntesis, la incondicionalidad e independencia del pensar ${ }^{21}$. Incluso la filosofía hegeliana, que cobra conciencia de la historicidad del pensar, acaba subordinando toda otra finalidad y responsabilidad a la libertad de pensar. Este cuestionamiento levinasiano se proyecta ante todo a la así denominada «filosofía primera», que indica desde Aristóteles el modo más fundamental de relacionarse con el ser y de conocer su estructura, siendo la teología, la ontología y la epistemología los principales campos de exposición de este conocimiento inicial. Por eso, la famosa expresión con que Levinas titula su conferencia de

20 Franz Rosenzweig, El nuevo pensamiento, 77.

21 Emmanuel Levinas, Éthique comme philosophie première (Paris: Payot \& Rivages, 1998), 71. 
1982, «Ética como filosofía primera», sintetiza el motivo central de su filosofía al mismo tiempo que su particular comprensión de la ética: la ética es ante todo una relación originaria con el Otro, en la cual el sujeto es convocado a la responsabilidad por el Otro, y su respuesta es su subjetivación misma, su identidad ${ }^{22}$. El infinito es el término con que se expresa esta relación desde siempre convocante y nunca totalmente acabable en una acción o concebible con un concepto o una donación de sentido. Es una relación que precede, sucede y excede al orden del ser, que reduce siempre los términos relacionados a una presencia y a una entificación. Se concentra aquí in nuce toda la crítica levinasiana a la onto-teología, así como sus reparos ante toda política (pero también todo sistema institucional, jurídico y religioso) que no atienda antes y después de toda construcción al llamado de la responsabilidad y su temporalidad.

Esta crítica de Levinas al supuesto primado ontológico o gnoseológico de la filosofía occidental alcanza también al modelo entificante de lo divino que caracterizó a la teología. Levinas no propone a cambio un tipo de irracionalidad o de exaltación que fusione el sujeto con lo divino, sino al contrario: la separación es condición de trascendencia, y la trascendencia es lo que posibilita el tipo de llamado que origina la relación. La filosofía que aborda esta relación es una «nueva racionalidad» distinta de la antigua teología presa de la ontología ${ }^{23}$. Cuando la teología tradicional entendía la creación en términos entificantes, o sea, en términos causales o productivos de un Dios eterno que debe salir de la eternidad y la espiritualidad para hacer tiempo y materia, se veía inmersa en tensiones aparentemente insuperables, siendo que ya en la idea platónica de Bien más allá del Ser está inscripta una trascendencia como punto de partida, la imposibilidad de totalizar las relaciones en

22 Emmanuel Levinas, Éthique comme philosophie première; Emmanuel Levinas, Ethique et infini. Dialogues avec Philippe Nemo (Paris: Fayard et Radio-France, 1982), 81.

23 Emmanuel Levinas, De Dieu qui vient à l'idée (Paris: Vrin, 1982), 86. Un minucioso análisis de esta nueva racionalidad puede hallarse en el texto de Mariana Leconte, Racionalidad y proximidad (Corrientes: Moglia, 2009). 
una inmanencia ${ }^{24}$. La relación con el Otro tiene la misma estructura: me antecede de modo inmemorial, me demanda y escapa a toda capacidad subjetiva propia que de un sentido o acción que «cierre». Ni la analogía permite un modelo de conocimiento que resuelva el vínculo con la trascendencia y la tensión subjetiva hacia esta. Por eso, aunque la mayoría de las referencias textuales en Levinas fundamentan una crítica al concepto de «teología» imperante en el pensamiento occidental, incluida la «teología negativa», también se hallan afirmaciones que posibilitan otro punto de partida para el lenguaje sobre Dios. Por ejemplo, cuando pluraliza el término («teologías») para liberarlo de la pretensión dogmática y acercarlo al modo rabínico de reflexionar sobre Dios ${ }^{25}$, o cuando lo acerca a la experiencia fundamental -que en otros momentos llamó «religión»al decir que «la teología comienza en el rostro del prójimo» ${ }^{26}$, lo que hace es ofrecer una alternativa no irracionalista del discurso sobre Dios, que al mismo tiempo reconozca el vínculo fundante con la alteridad, su irreductibilidad, y su continua insubordinación al dominio del concepto.

Un pensamiento de lo Otro divino e infinito es un tipo de relación que no se ocupa ante todo por la existencia o las propiedades de lo relacionado, como en el caso de las pruebas de la existencia de Dios, sino de cómo significa esa relación en la relación misma con la proximidad del otro ser humano ${ }^{27}$. Se trata de una de las «experiencias no-filosóficas» que anteceden y transforman al filosofar mismo ${ }^{28}$. No se trata de argumentar lógicamente o de indagar conceptualmente lo implicado en el acontecimiento de relación con lo divino, ni siquiera para acabar en una teología negativa o una sijética. Todos estos

Emmanuel Levinas, Totalidad e infinito (Salamanca: Sígueme, 1995), 297. De aquí que, al igual que sucede con Rosenzweig, el monoteísmo deba replantearse su comprensión de qué significa creación en términos no ontológicos. Casper revisa críticamente la comprensión causal y productiva de la creación desde la idea relacional del sujeto ético, Bernhard Casper, Pensar de cara a otro. Elementos del pensamiento de Emmanuel Levinas (Córdoba: EDUCC, 2007), 75-90.

25 Emmanuel Levinas, L 'au-delá du verset (Paris: Les Éditions du Minuit, 1982), 11.

26 Emmanuel Levinas, Les imprévus de l'histoire (Paris: Fata Morgana, 1994), 202.

27 Emmanuel Levinas, $L$, au-delá du verset, 252.

28 Emmanuel Levinas, De otro modo que ser o más allá de la esencia (Salamanca: Sígueme, 1987), 191. 
modelos son modos de tematizar, reducir lo infinito a la lógica de la presencia y el concepto, lo cual significa que ese tipo de lenguaje teológico destruye la situación religiosa de trascendencia. Todo signo entifica el significado an-árquico, produciendo definiciones y deduciendo "verdades de la fe ${ }^{29}$. Pero tampoco es teología negativa porque la «negatividad» que expresa lo Otro tiene un vuelco positivo en la acción responsable por el Otro a la que lleva ${ }^{30}$. La condición en que la palabra Dios viene al pensamiento puede ser descripta diciendo que «la revelación es amor al otro hombre», "que la relación con lo absoluto o infinito significa éticamente, es decir en la proximidad del otro hombre, del extranjero y posiblemente desnudo, pobre y no deseable, pero también en su rostro, que me exige en el rostro dirigido a mí de modo irrecusable, que me cuestiona» ${ }^{31}$. Según Levinas, la teología lleva a cabo una traición al poner esta experiencia en lo «dicho», «tematizándolo». No puede hacer la teología otra cosa, pues el logos es necesario cuando intenta utilizar un lenguaje que haga viable la comunicación de una experiencia, pero al hacerlo claramente hay una pérdida. Y sin embargo la palabra es «kerigma» y puede mantener la «huella del exceso» ${ }^{32}$.

La teología tradicional no logra dar cuenta del exceso que se opera en el contacto con el infinito. Este exceso es el mismo que opera en la relación con el otro ser humano. No es casual, entonces, que este vínculo con lo otro-infinito, relación primera con la alteridad, sea llamado por Levinas tanto «ética» como «religión». No es «ética» al modo de la constitución de un ethos virtuoso, ni lo es en el sentido de un modelo de construcción de normas. Tampoco es «religión» al modo de institución cultual, ni lo es en el sentido de un servicio «debido» a la divinidad, ni significa, finalmente, algún tipo de conmoción irracional ante el misterio. Se trata, en cambio, de entender la ética como una relación con Otro que siempre antecede y escapa a las potencias

29 Emmanuel Levinas, De otro modo que ser o más allá de la esencia, 192

30 Emmanuel Levinas, De otro modo que ser o más allá de la esencia, 56.

31 Emmanuel Levinas, De Dieu qui vient à l'idée, 252

32 Emmanuel Levinas, De otro modo que ser o más allá de la esencia, 229. 
subjetivas, una relación que no puede totalizarse ni reducirse a un concepto; una relación demandante, con una exigencia que subsiste y se incrementa luego de cualquier respuesta. La ética, en esta descripción, es estructura primera. Y la religión, «en la que la relación subsiste entre el Mismo y el Otro a pesar de la imposibilidad del todo», es igualmente «la estructura última» ${ }^{33}$. Si la teología fallaba al no dar cuenta de la relación por un «olvido» de la experiencia inicial, por su conversión en ontoteología y metafísica, y por entender trascendencia como trasmundo ${ }^{34}$, también falla la reducción de toda relación a lo político. «La distancia que separa felicidad y deseo, separa política y religión. La política tiende al reconocimiento recíproco, es decir, a la igualdad: asegura la felicidad. Y la ley política acaba y consagra la lucha por el reconocimiento. La religión es Deseo y no lucha por el reconocimiento. Es la excedencia posible en una sociedad de iguales» ${ }^{35}$. La indispensable política es una serie de mecanismos y razonamientos que pretenden asegurar el reconocimiento y la igualdad, condiciones para la felicidad social. Estos mecanismos no excluyen la lucha, y por lo tanto están siempre en riesgo de servir a fines muy distintos de aquellos que supuestamente se apuntan al inicio de la relación interhumana. Sucede que si el deseo por el Otro, en sentido levinasiano de una tensión-hacia o un ser-para-laresponsabilidad por el otro y su mandato de vida, no está al inicio, se corre el riesgo de convertir al resultado o a la aspiración colectiva de felicidad en un argumento que soslaya los requisitos de la relación cara a cara con el Otro ${ }^{36}$.

Contra toda totalización o subsunción bajo cualquier orden institucional, el orden ético-religioso, en sentido levinasiano, es «el reconocimiento del individuo» en su singularidad y menesterosidad,

\footnotetext{
Emmanuel Levinas, Totalidad e infinito, 103.

Emmanuel Levinas, De otro modo que ser o más allá de la esencia, 42, 48.

Emmanuel Levinas, Totalidad e infinito, 87.

Bernhard Casper encuentra en la socialidad que se postula como absoluta o el vínculo político que solo alude a sí mismo sin dejar un resto, uno de los modos de idolatría y caída de lo religioso. Bernhard Casper, El acontecimiento de orar. Líneas fundamentales de una hermenéutica del evento religioso (Córdoba: Alción, 2011), 143.
} 
en su reclamo que llama a la responsabilidad del sujeto ${ }^{37}$. Este reconocimiento del Otro significa un punto de partida de experiencia y pensamiento, que limita las prerrogativas de instituciones y sistemas políticos y, en última instancia, de la historia misma. Levinas entiende que la teoría política fundamenta la justicia desde la exigencia de reconocimiento y la fuerza de la espontaneidad en el seno de una totalidad ${ }^{38}$. Esta construcción de institución política en la historia no es rechazada por Levinas, sino que encuentra un valor de verdad en esta realidad, ya que «la libertad apolítica se explica como una ilusión» ${ }^{39}$. O sea, la experiencia concreta de la libertad que se hace cargo de la responsabilidad, es segunda respecto de la responsabilidad, pero requiere de modo imprescindible de la política y sus configuraciones. Pero estas no pueden por sí mismas librarse del impulso egoísta de individuos y colectivos. Por eso la historia y su temporalidad no indican una escatología desde la cual juzgar sus propias realizaciones, que son del orden de lo «visible» y la «evidencia». En cambio, el deseo de lo infinito y su manifestación en la bondad dan cuenta de algo invisible y no evidente; es necesario que esto se manifieste para que «la historia pierda su derecho a la última palabra, necesariamente injusta para la subjetividad, inevitablemente cruel $»^{40}$.

Esta «nueva racionalidad» que Levinas propone tiene explícitas consecuencias sociales en tanto pretende también ser una «racionalidad de la paz» ${ }^{41}$. La paz aludida no desconoce el trabajo político ni el orden «lógico»y formal de la justicia institucional, pero lo excede. Son importantes las alusiones levinasianas a lo político, sobre todo por un contenido material que a menudo en la historia del siglo xx fue visto como mutuamente contradictorio: la política es el trabajo de

Emmanuel Levinas, Totalidad e infinito, 256.

Emmanuel Levinas, Totalidad e infinito, 105. Es importante aclarar un giro significativo en el pensamiento levinasiano sobre la justicia: mientras que en Totalidad e Infinito la justicia está relacionada con el logos que busca igualar diferencias mediante el recurso al concepto y por medio de las instituciones, en De otro modo que ser y la obra posterior la justicia es la relación originaria misma de responsabilidad como respuesta al otro inconmensurable.

39 Emmanuel Levinas, Totalidad e infinito, 255.

40 Emmanuel Levinas, Totalidad e infinito, 257.

41 Emmanuel Levinas, De otro modo que ser o más allá de la esencia, 239 
suplir necesidades, la política es la institucionalización de un orden de igualdad y la política debe reconocer las particularidades, de modo tal que sean siempre revisables sus decisiones ${ }^{42}$. La estructura platónica del bien más allá del ser da la posibilidad de un orden moral que antecede y regula las decisiones prácticas, sin consumar en ellas el orden mismo. Pero la justicia de la racionalidad levinasiana no puede fusionarse con ese orden platónico ${ }^{43}$. La ética primera que Levinas propone garantiza el orden de la pluralidad mediante una comprensión de la bondad como relación con el otro: el deseo del otro rechaza «la ontología de la subjetividad aislada y la ontología de la razón impersonal que se realiza en la historia» ${ }^{44}$. Esencialmente el sujeto es hospitalidad, recepción, responsabilidad por lo que recibe. El Estado político intenta gestar la unicidad, reducir lo múltiple a la universalidad del Estado al modo de la homogeneidad y reducción de lo otro ${ }^{45}$. Sin desconocer la necesidad del Estado político, Levinas sostiene que su reducción al orden de la razón o de la necesidad natural conlleva la aniquilación de las condiciones de posibilidad de la alteridad, de su reclamo, y de la propia subjetividad en tanto responsabilidad.

\section{Recapitulación: la imposible e imprescindible teología política}

Las críticas de Rosenzweig y Levinas a la teología como sistema abstracto, desligado de la comunicación acaecida y reducido a conceptos provenientes de la ontoteología, así como sus críticas a

42 Levinas ubica el trabajo político de modo primario al nivel de la necesidad, y por eso considera que el marxismo tiene la «sinceridad» de tomar como punto de partida político el hambre, Emmanuel Levinas, De la existencia al existente (Madrid: Arena, 2000), 58, y este reconocimiento es válido incluso a pesar del orden de cosas efectivamente constatable en los países socialistas. Respecto de la valoración del Estado liberal, como aquel que resiste al régimen absoluto e invariable, cf. Emmanuel Levinas, Autrement que savoir (Paris: Osiris, 1988), 62.

43 Como bien comenta Caputo, la justicia más allá de la ley y la venida de lo totalmente otro, el «exceso» del bien que Levinas liga con el platonismo, «es una idea que los amantes del reino pueden usar si se deja de lado la metafísica neoplatónica, que no tiene casi nada que ver con el reino», John Caputo, "The poetics of the impossible and the Kingdom of God», en The Blackwell Companion to Postmodern Theology, ed. Graham Ward (Malden-Oxford: Blackwell, 2005), 479.

44 Emmanuel Levinas, Totalidad e infinito, 309.

45 Emmanuel Levinas, Totalidad e infinito, 304. 
las experiencias políticas históricamente constatables que conducen a una eliminación de la pluralidad y de la experiencia ética originaria de responsabilidad por el otro, son manifestaciones que argumentarían claramente en contra de un pensamiento teológicopolítico en estos autores. Si bien hay una pasividad en ambos, ya que el inicio de la comunicación no se halla en los poderes del sujeto racional sino en su receptividad; y a pesar de que esa manifestación del Otro tiene el carácter y la autoridad de un mandato, para nada se asemeja eso al «pathos de la autoridad» que Schmitt encuentra en la Iglesia y su estructura legitimatoria del poder ${ }^{46}$. La noción de representación institucional que la autoridad eclesiástica imbrica en el orden temporal y que el Estado secular mantiene estructuralmente, se contrapone a la idea de comunicación de los separados -que no es complexio oppositorum- que permanecen siempre separados. Más aún, la idea de separación de Dios y del Otro -a pesar de requerir su comunicación al sujeto- conlleva garantizar la imposibilidad de reducción de Dios y Otro a fines prácticos institucionales. Una teología política pensada como garantía teológica de la acción pública sería simplemente inaceptable. Conviene recapitular las razones de esta inaceptabilidad, al mismo tiempo que revisar por qué estos pensadores suponen un giro teológico que vuelve imprescindible otro tipo de teología política.

Rosenzweig analiza una doble violencia que surge del lazo entre Estado político y teología: la implantación de una ley y la justificación de la guerra. Los pueblos entienden que su política está al servicio de su preservación y expansión, y este crecimiento tiene efectivamente un análogo teológico en tanto el cristianismo intenta llevar de modo misional su mensaje de redención a todos. Pero este mensaje tiene la paradoja de que es universalista e igualitario, aunque su historia efectiva generase la idea de «pueblos elegidos», que buscan eternizarse en el seno del mundo mediante la fuerza, y justifican así

46 Carl Schmitt, Catolicismo romano y forma política (Madrid: Tecnos, 2011), 23. 
religiosamente sus guerras ${ }^{47}$. Frente a esta comprensión inmanentista de lo teológico-político, Rosenzweig ofrece una perspectiva disruptiva: la «política mesiánica» ${ }^{48}$, que adopta el punto de vista del pueblo que no debe ya crecer ni extenderse, que desmiente tanto la eternidad que pretende proveer el Estado en la doble violencia de la ley y la guerra ${ }^{49}$. El requisito de «expansión» acerca demasiado el requisito misionero cristiano a la preservación estatal ${ }^{50}$. Rosenzweig ve este vínculo del cristianismo con el Estado como algo peligroso y necesario. Su peligro está ligado a los «peligros cristianos» en general, que espiritualizan al concepto de Dios, hacen una apoteosis del hombre y panteizan al mundo ${ }^{51}$. Al recordar al judaísmo que la redención debe darse en el mundo, el riesgo general de divinizar la acción del Estado en el mundo significa olvidar la trascendencia. Pero una teología cristiana que atiende a la experiencia judía se eleva contra ese riesgo, ya que niega que ese camino sea el Reino mismo y que la historia sea de por sí sacra.

También Levinas tiene una cercana experiencia de la guerra y su violencia, tanto que Mosès ve en la meditación sobre la guerra el puente entre la Estrella y Totalidad e Infinito ${ }^{52}$. El uso político de Dios para la guerra es refutado precisamente desde la experiencia religiosa monoteísta. El monoteísmo del pueblo elegido demuestra que toda guerra es finalmente política, y que el uso de Dios para justificarla es un uso espurio ${ }^{53}$. Ambos pensadores presentan de modo particular la experiencia de una individualidad que debe ser reconocida y respetada, pero no al modo del sujeto individual moderno, fuente y origen de sí y de toda razonabilidad, sino al modo de un sujeto «investido» por Otro al punto de la «obsesión»

\footnotetext{
47 Franz Rosenzweig, La Estrella de la Redención, 391-392.

48 Franz Rosenzweig, La Estrella de la Redención, 389.

49 Franz Rosenzweig, La Estrella de la Redención, 393-394.

$50 \quad$ Franz Rosenzweig, La Estrella de la Redención, 474.

51 Franz Rosenzweig, La Estrella de la Redención, 471.

52 «From Rosenzweig to Levinas: Philosophy of War», en Political Theologies. Public Religions in a PostSecular World, eds. Hent de Vries y Lawrence E. Sullivan (New York: Fordham University Press, 2006), 221.

53 Cf. Franz Rosenzweig, La Estrella de la Redención, 391-393.
} 
por ese Otro que se comunica, le comanda ser responsable y en esa comunicación en que surge una responsabilidad el propio sujeto se reconoce como responsabilidad. No hay aquí un arché o una relación entre dos entidades que conozca un origen en el tiempo. No hay un principio ab-soluto que se imponga y dé inicio a una relación, como el que se pensaba necesario para la soberanía y el Estado. En términos de Levinas, hay una an-arquía, en la que el sujeto se descubre desde-siempre-ya en relación con Otro, llamado por Otro. De manera paradójica, el significado de la comunicación ética que se manifiesta en esa falta de inicio permite el modo más genuino de definir lo religioso: «en nuestro modo de interpretar la significancia, la práctica (y lo religioso inseparable de la práctica) se define por lo an-árquico. La teología solo sería posible como la contestación del religioso puro, confirmándolo tan solo a través de sus fracasos o de su lucha $»^{54}$. La ontoteología fracasa al intentar exponer la relación originaria, que Levinas llama ética y religión. Pero el fracaso permite precisamente exponer la anarquía de una relación que rompe los modelos de justificación de las éticas canónicas, las razones de Estado y las justificaciones teológico-políticas.

A pesar de los resguardos y críticas respecto de los modos de configurar lo político efectivamente realizados, y a pesar de todas las críticas posibles desde la «teoría del conocimiento mesiánica» de Rosenzweig y de la ética levinasiana, el requisito de plasmar con formas viables el contenido primario de responsabilidad al que se accede en la comunicación más elemental con el Otro -en términos levinasianos: pasar del Decir al Dicho - es algo imprescindible ${ }^{55}$. Caso contrario se permanecería en el voluntarismo inocuo pero estéril (y en esa medida cómplice) de las almas bellas. La ética es el vínculo que despierta el sujeto al Otro y su mandato, expresado como requisito de vida y de las condiciones materiales para la misma. Pero este mandato requiere mediaciones, que incluyen no solo la acción

54 Emmanuel Levinas, De otro modo que ser o más allá de la esencia, 186.

55 Emmanuel Levinas, De otro modo que ser o más allá de la esencia, 86. 
de proveer, sino también de todas las producciones que permitan esa provisión. Vale rescatar dos aspectos elementales: en primer lugar, la política debe lidiar con el ámbito de lo que Totalidad e Infinito llama la «necesidad»: la «función primera de lo político» es responder al hambre de los hombres ${ }^{56}$. Pero además, en su lectura talmúdica «Más allá del Estado en el Estado», Levinas recupera la interpretación de la política colonialista de Alejandro Magno, como paradigma de la política que es un deseo insaciable de bienes que genera violencia. Y sin embargo el mismo texto plantea las demandas de la Torá, que indica una «diferencia radical entre lo que puede haber de válido en una política razonable, de un lado, y la justicia auténtica, del otro ${ }^{57}$. La política no es un fin en sí; es pragmática, en tanto orientada a satisfacer necesidades, y es imperfecta, en tanto no cierra en sí y sus razones prácticas, sino que está impulsada por un deseo de justicia y plenitud que exceden la inmanencia. Pero el objetivo de estas páginas no es indagar las condiciones políticas que se desprenden de las filosofías de ambos pensadores. Más allá de las formas de vehiculizar una construcción posible desde Rosenzweig y Levinas, es preciso aquí desarrollar un criterio o condición de evaluación de toda construcción, íntimamente ligado con la experiencia subjetiva de la temporalidad en ambos pensadores, así como también de la relación que esa temporalidad subjetiva tiene con la historia efectiva.

\section{La temporalidad de la existencia ante Otro}

El modo de pensar dialógico de Rosenzweig implica obligatoriamente tomar en serio el tiempo. Nada se da sub specie aeternitatis, ni siquiera la «eternidad» del pueblo judío que ya está en la meta, pues su existencia sigue funcionando al interior del tiempo como parámetro para entender y juzgar la historia. A pesar de ser pueblo eterno, su vida se manifiesta en y paralela a la historia, testimoniando otro tipo de temporalidad que mira al pasado irrecuperable aunque vigente

56 Emmanuel Levinas, L 'au-delá du verset (Paris: Les Éditions du Minuit, 1982), 34.

57 Emmanuel Levinas, Nouvelles lectures talmudiques (Paris: Les Éditions de Minuit), 1996, 76. 
de la creación, a la comunicación siempre renovada de la revelación y al futuro que permanece siempre futuro de la redención. Así, una filosofía que se disponga a trabajar en colaboración con la teología toma en cuenta la experiencia del pasado que provee la noción de creación ${ }^{58}$. La idea de la «vieja» filosofía y teología relacionaba la idea de creación con la de arbitrariedad divina, que amenaza con «desligar a ese Dios», rompiendo su relación ${ }^{59}$. En cambio, pensar la creación como un proceso que incluye ya revelación y redención en su inicio, implica poner en juego la «menesterosidad de la criatura» y su dirección hacia un pasado y un futuro no-disponibles ${ }^{60}$. Esto implica separación y comunicación, lo que se muestra claramente cuando Levinas relaciona separación con tres aspectos: ruptura del orden cronológico de la temporalidad en tanto aparición de un sujeto capaz de libertad; ateísmo en tanto ruptura con la participación y capacidad de individualidad independiente; y finalmente creación en tanto pluralidad consciente de no ser origen de sí misma ${ }^{61}$. Al igual que Rosenzweig, Levinas relaciona creación y revelación: «La maravilla de la creación no consiste solamente en ser creación ex nihilo, sino en lograr un ser capaz de recibir una revelación, de aprender que es creado y capaz de cuestionamiento. El milagro de la creación consiste en crear un ser moral» ${ }^{62}$.

El «tiempo» de la creación supone el «estar-ya-ahí» del mundo y de sí, se da al modo de la facticidad de un mundo que «se hace nuevo cada mañana» ${ }^{63}$. En esa renovación cotidiana se manifiesta el presente como revelación. La imagen por antonomasia es la del amor terrenal, que es un «suceso que sucede», una irrupción, que niega todo lo vigente y se impone con la fuerza del pathos ${ }^{64}$. La creación es revelación en tanto una y otra vez se confirma en el tiempo; pero la

\footnotetext{
Franz Rosenzweig, La Estrella de la Redención, 145.

Franz Rosenzweig, La Estrella de la Redención, 157.

Franz Rosenzweig, La Estrella de la Redención, 164.

Emmanuel Levinas, Totalidad e infinito, 77.

Emmanuel Levinas, Totalidad e infinito, 111.

Franz Rosenzweig, La Estrella de la Redención, 174-175.

Franz Rosenzweig, La Estrella de la Redención, 205.
} 
revelación es esa confirmación una y otra vez explicitada y aceptada, la recepción renovada del mandato de amor. Aquí hay una relación de dos necesidades, la humana y la divina, ya que el ser humano deviene quien es respondiendo al mandamiento, pero al mismo tiempo sin ese testimonio Dios no es totalmente Dios ${ }^{65}$. Finalmente, el tiempo abierto es el del futuro que no se encierra en una figura rígida y trágica, heroica pero incomunicada, como en la tragedia antigua y moderna. El mundo muestra su inacabamiento no solo en la experiencia del mal y de la imperfección, sino en la vocación inherente al amor de romper el límite de los amantes y abrirse a los otros, al prójimo, en un movimiento inacabable. Ese movimiento no se acaba porque «es lo que debe venir. Es el Reino» ${ }^{66}$. El Reino «viene eternamente», no cristaliza ni entifica su realidad en una construcción «de una vez por todas» ${ }^{67}$. En síntesis: la «temporalidad del nuevo pensamiento" se revela sobre todo en el libro central de la Estrella, en que el presente como revelación del mandamiento de amor abierto a todo otro, mira atrás y adelante: "solo vistos desde aquí el comienzo y el fin se convierten, de conceptos-límite de la infinitud, en mojones de nuestra posesión de mundo; el "comienzo" en creación, el "fin" en redención ${ }^{68}$. De ese modo, la experiencia individual se ubica en un sentido de temporalidad hacia-Otro.

Sin ligar explícitamente como Rosenzweig la temporalidad con las tres «categorías» monoteístas, también Levinas vincula el presente con un mandato del Otro que nace en un pasado más allá de toda recolección o fijación cronológica. Debido a que este tiempo relacional no es una secuencia ni acontecimientos dentro de una secuencia, vale también aquí la afirmación de Rosenzweig: «nada de lo que sucede sucede en el tiempo, sino que él, él mismo, sucede» ${ }^{69}$. El tiempo es relación con el Otro, lo que permite ante todo una doble ruptura: la

65 Franz Rosenzweig, La Estrella de la Redención, 216.

66 Franz Rosenzweig, La Estrella de la Redención, 268.

67 Franz Rosenzweig, La Estrella de la Redención, 273.

68 Franz Rosenzweig, La Estrella de la Redención, 262.

69 Franz Rosenzweig, El nuevo pensamiento, 58. 
ruptura de la inmanencia al ser anónimo y sin sujeto, que Levinas llama «hay», pero también la ruptura del sujeto como «hipóstasis» o posición autofundante, separada del anonimato y de los demás entes. La relación con Otro genera en primer lugar una discontinuidad en el tiempo, pero al ser relación esa discontinuidad no está cerrada. Se abre en figuras como la obra, la fecundidad, la responsabilidad. Hacia el pasado, no hay una fijación o contrato, acta de nacimiento cronológica de esa responsabilidad en la que surge al mismo tiempo la propia identidad. An-arquía que no solo caracteriza sino además explica el porqué de la no-originariedad en sí tanto del mandato como de la fuerza de respuesta. Pasado que el recuerdo no puede recuperar, sin arché ni sincronía de la conciencia-de. «Podría llamarse a esto apocalípticamente estallido del tiempo», dice Levinas, pero es una diacronía que a cada momento es indicio de lo inmemorial, que es un profundo pasado, jamás suficientemente pasado ${ }^{70}$. Al mismo tiempo, esta "apocalíptica» revela un tipo de futuro: apertura a lo radicalmente nuevo, al «triunfo puro», al «tiempo mesiánico» de responsabilidad acabada por el Otro ${ }^{71}$. Futuro que permanece futuro, pero que tensa el sujeto hacia sí.

\section{Lo político como espacio de intervención en la historia y la cuestión judeocristiana}

La aseveración de que el Reino o el tiempo mesiánico no es idéntico a los pasos necesarios para preparar su advenimiento, de que ninguna realización en el tiempo hará cesar los anhelos o cerrará las demandas, o en términos levinasianos, de que el Deseo del Otro que el Decir intenta exponer jamás puede cerrarse en la exposición concreta de un Dicho, permite evitar críticas como las que Voegelin formula respecto de toda política que asuma características religiosas ${ }^{72}$. El

\footnotetext{
70 Emmanuel Levinas, De otro modo que ser o más allá de la esencia, 172.

71 Emmanuel Levinas, Totalidad e infinito, 292.

72 Eric Voegelin, «The Political Religions», en Modernity Without Restraint, The Collected Works of Eric Voegelin Vol. 5 (Columbia-London: The University of Missouri Press, 2000), 19-74.
} 
riesgo que Voegelin certeramente ve en los totalitarismos aplica también a los modelos más tecnocráticos o liberales de gestionar lo público, en tanto no asumen que haya una norma más allá de sí que pueda regular críticamente sus realizaciones. Se han suscitado innumerables tensiones entre lo religioso-teológico y lo político, que se acentúan desde el surgimiento de los Estados modernos. La teología, como actividad reflexiva de prácticas y creencias a la luz de aportes filosóficos y científicos, no escapa a estas tensiones. Sin embargo, la tensión que el futuro instaura en el sujeto afecta a sus realizaciones en vistas de ese final. «iRetrasar o acelerar el final?» titula Reyes Mate un esclarecedor artículo respecto de una tensión esencial a la teología política, en vistas al vínculo entre Schmitt y Taubes $^{73}$. La cuestión de la escatología, del final, es un problema central de toda teología política. Incluso Schmitt -que privilegia la temporalidad del katechon a la del eschaton, es decir, que acentúa la importancia de la gestión del orden pre-escatológico y sus consecuencias institucionales y políticas antes que centrar la fuerza motora de la acción en la idea de final de la temporalidad-reconoce en su propio deseo de postergación del final la idea de acabamiento como aquello que da sentido y dirección a la acción. Por eso los pensadores influidos por la «nueva» teología política desde Schmitt se han considerado siempre en las antípodas del gnosticismo, que inmanentiza la historia y fusiona en una misma realización el final esperado y los pasos hacia el mismo.

Rosenzweig y Levinas proponen una relación tensa entre dos actitudes que generan modos de temporalidad aparentemente opuestos. Por un lado, el deseo y la oración del creyente que quiere acelerar la llegada del Reino es, según Rosenzweig, la expresión más clara de relación tanto con el Reino mesiánico como con los diversos pasos que al interior del tiempo se dan hacia él. Por su parte, la paciencia en sentido levinasiano indica que el sujeto no se entiende

73 Manuel Reyes Mate, «Retrasar o acelerar el final», en Nombres. Revista de Filosofía 21, Vol. xvII (2007): 17-33. 
como conciencia intencional que dona sentido al tiempo, sino como recepción y hospitalidad de un mandato imposible de asumir, a cuya luz se envejece.

\subsection{La tiranía como condición constitutiva de la temporalidad en Rosenzweig}

Una comprensión adecuada del funcionamiento de creación, revelación y redención en la filosofía de Rosenzweig no solo sirve para comprender esta filosofía misma sino el modo de temporalización de los sujetos que da a luz y que es objetivo central de estas páginas. También cabe decir que una comprensión adecuada permite la crítica y denuncia de los modos y sistemas inadecuados de vinculación teológico-política, como aquel que va «de Hegel a Bismark» ${ }^{74}$, que intentaba reunir en un mismo Reino las conquistas institucionales europeas, la religión cristiana y la filosofía idealista. De ese Reino solo queda un «campo de ruinas» cuando Rosenzweig publica su tesis doctoral, un libro que en su origen pretendía renovar la idea estatal de Hegel adaptándola a nuevas realidades (como las nociones de pueblo y nación) y del que afirma en su prefacio que «hoy [1920] ya no lo habría escrito ${ }^{75}$. En vistas de la debacle, pero incluso antes ya por razones filosóficas y religiosas, Rosenzweig comienza a ligar su crítica de la historia con una crítica de la política, lo que se manifiesta de modo patente en la Estrella ${ }^{76}$. Por eso, la comprensión de Rosenzweig de la historia y la temporalidad es al mismo tiempo crítica y esperanzada, porque la ubica en un marco de comprensión distinto, en que pasado, presente y futuro se ligan a categorías teológicas como creación, revelación y redención. Así, esta filosofía no diviniza a la historia, justificando bajo una teodicea cualquier

74 Franz Rosenzweig, Hegel und der Staat. Zweiter Band: Weltepochen (München und Berlin: Oldenbourg, 1920), 245.

75 Franz Rosenzweig, Hegel und der Staat. Erster Band: Lebenstationen (München und Berlin: Oldenbourg, 1920), XIII.

76 Stéphane Mosès, «Hegel beim Wort genommen», en Gottard Fuchs y Hans Hermann Henrix, Zeitgewinn: Messianisches Denken nach Franz Rosenzweig (Frankfurt: Knecht, 1987), 71. 
injusticia o barbarie, sino que entiende la acción divina y humana en la historia en los acontecimientos éticos puntuales y concretos.

¿Cómo entender filosóficamente la disposición subjetiva que Rosenzweig encuentra en la relación con el final y con las elaboraciones políticas concretas? La relación con el Reino es un acicate subjetivo, que puede manifestarse a modo de tentación en aquellos que pretenden acelerar el tiempo del Reino. Si bien la tentación tiene la característica, en términos heideggerianos, de un «existencial», la doble tentación -de Dios al hombre y del hombre a Dios- instaura un movimiento de expectativa y acción. En este movimiento, la impaciencia conlleva el riesgo de forzar tiempos imprudentemente, justificar acciones irresponsablemente e identificar lo provisorio con lo definitivo. El «crecimiento del Reino»y su acción de «estar siempre viniendo» requieren de una anticipación activa: esta espera activa es "ella misma un forzar ese acto» ${ }^{77}$. Es decir, no se trata de una relación quietista, ya que el Reino lejano «se espera a cada momento» y esto acicatea la acción y la plegaria, atando ambas al mundo.

Los tiranos, contra quienes está dedicada la tercera parte de la Estrella, desconocen esta separación e intentan vencer la tensión arrojándose a uno de sus extremos. Es por esto que Rosenzweig se niega a ver en a Dios en la historia, pues esto canonizaría a la historia y justificaría todo el mal en ella. «Vemos a Dios en cada acontecimiento ético, pero no en el todo acabado» ${ }^{78}$. Aparece algo paradojal: se asume la necesidad del tiempo y del Otro, pero afirmando un principio extratemporal y trascendente a la historia para juzgarla. Los tiranos del Reino intentan acelerar los tiempos, pero logran lo contrario, lo retrasan ${ }^{79}$. La posibilidad de tentar a Dios para que acelere su venida no indica una desviación, sino que es

\footnotetext{
77 Franz Rosenzweig, La Estrella de la Redención, 273, 277.

78 Franz Rosenzweig, Briefe und Tagebücher 1918-1929, Gesammelte Schriften 1, Band 2 (Den Haag: Martinus Nijhoff, 1979), 112.

79 Franz Rosenzweig, La Estrella de la Redención, 326.
} 
el motor de la «ejecución viva de la verdad», que se ofrece en dos manifestaciones: el camino cristiano de expansión del mandamiento del amor y el camino judío de juicio de las diversas concreciones históricas de esa expansión ${ }^{80}$.

\subsection{La paciencia como condición constitutiva de la praxis ético- política en Levinas}

La fenomenología husserliana ya había descubierto que hay una pasividad en la conciencia del tiempo, una impresión primaria, original, que antecede siempre a toda donación de sentido y representación. Levinas lleva adelante esa fenomenología, la radicaliza, afirmando que «la temporalización del tiempo, lapso irrecuperable y fuera de toda voluntad, es todo lo contrario que la intencionalidad ${ }^{81}$. Es lo contrario porque el lapso no puede ser cerrado, porque la temporalidad implica la "pasividad de su paciencia» que rompe el poder del sujeto tematizante. Este sujeto padece un sufrir, una pasividad, que se manifiesta por antonomasia en la senescencia, el envejecimiento que «se» padece, que «pasa», como un verbo sin sujeto. Esto que sucede «al margen del tiempo rememorable», como una vida vivida a la luz de una huella o una obsesión que se porta sin saber muy bien desde y hasta cuándo. Este padecimiento es una «bondad a su pesar», una bondad pequeña pero que vulnera una y otra vez las defensas subjetivas. Esto no significa abstenerse de la acción pública, pero la somete a un juicio que se diferencia de los parámetros utilitaristas o los deontológicos. Por un lado, el hambre exige una política activa, que corre el riesgo de elaborar un entramado en el que las imposiciones para satisfacer la necesidad generen injusticia. De allí se desprende no solo la necesidad de revisión constante, antes expuesta, sino también la sospecha sobre todo régimen que pretenda regular el ejercicio del bien. Por eso, hay una «imposibilidad de la bondad como régimen, como sistema organizado, como institución social», y eso se manifiesta

80 Franz Rosenzweig, La Estrella de la Redención, 487.

81 Emmanuel Levinas, De otro modo que ser o más allá de la esencia, 108. 
con el giro «pequeña bondad» ${ }^{82}$. Es bondad «fuera de todo sistema, de toda religión, de toda organización social. Gratuita, esta bondad es eterna» ${ }^{83}$.

La identidad personal se remite a la paciencia vivida como lapso irrecuperable, a la responsabilidad por esa huella que el sujeto porta. Pero la paciencia significa también una relación con el futuro, con la espera. Esta espera de un futuro siempre más justo, de más reconocimiento del otro, es espera mesiánica. Tampoco aquí es un quietismo: «Espera mesiánica, momento importante en que el futuro como éxtasis de un por-venir significa originalmente a partir de lo concreto de la respuesta al otro hombre» ${ }^{84}$. Es la subjetividad como espera del tiempo sin derrotas, pero que no se da como tal sino en cada acto de responsabilidad por el Otro. La paciencia es attente, exposición atenta al llamado del Otro que se prolonga en el tiempo. El envejecimiento señala lo irrecuperable de esta exposición, «identificación del yo como envejecimiento de lo que jamás "se recuperará"» ${ }^{85}$. La paciencia tanto como atención prolongada y pérdida irrecuperable permite un contrapeso a la impaciencia que es motor de la acción y que puede degenerar en tiranía.

\section{Conclusión: Paciencia e impaciencia mesiánica}

Hay un pathos originario de toda experiencia comunicativa que genuinamente tome en serio al Otro y al tiempo, o sea, la recepción y espera del Otro, así como la respuesta activa en el movimiento hacia el Otro. Esto conlleva entender al tiempo presente como provisorio, como camino hacia ese otro, e impone un tipo de relación particular con su advenimiento. Puede parecer prima facie impropio utilizar el concepto de «teología política» para comprender las filosofías de Rosenzweig y Levinas, máxime habida cuenta del contexto de

85 Emmanuel Levinas, De otro modo que ser o más allá de la esencia, 112. 
surgimiento de la «nueva teología política» con Schmitt. $Y$, sin embargo, la influencia de Schmitt ha alcanzado a diversos pensadores judíos, contándose a Benjamin, Strauss y Taubes entre los más conspicuos $^{86}$. El rechazo filosófico de un pensamiento soberano, inicio y fin de sí y origen de su potencia, tanto en Rosenzweig como en Levinas, dan como consecuencia teológica la mutua dependencia de las realidades relacionadas, así como la doble imposibilidad política tanto de una causa sui originaria de la legitimidad como de una representatividad total de dicha causa primera. A diferencia de lo formulado por la teología política de origen schmittiano, no es la soberanía del origen y la posibilidad de representarlo donde se da la relación teológico-política y su capacidad de legitimación, sino en la responsabilidad pública que cabe a quien ha asumido la responsabilidad de un llamado inmemorial y la tensión hacia un futuro de justicia. Pensadores teológico-políticos actuales como Metz acuerdan en el núcleo transversal a Rosenzweig y Levinas, entre otros, que ven al pensamiento como rememoración, anamnesis tanto de las responsabilidades humanas como de las catástrofes e injusticias que reavivan una y otra vez ese recuerdo ${ }^{87}$.

$\mathrm{El}$ «recuerdo» de la responsabilidad genera un tipo de subjetividad no reducida a la buena conciencia individual, sino políticamente activa. Tal actividad se vuelca de modo impaciente hacia adelante, intentando realizar acciones que permitan, en términos de Rosenzweig, que el Reino crezca. Pero la paciencia levinasiana implica cierto escepticismo o crítica respecto de las realizaciones concretas, la necesidad de reconocer el lapso irrecuperable entre llamamiento y respuesta, entre la magnitud de las demandas del Otro y la finitud y correctibilidad de las respuestas. La «era mesiánica» es un impulso legible en toda nación que efectúe políticas tendientes hacia la fraternidad, que apunten a una liberación, que asuma las

86 Cf. Leo Strauss, Jewish Philosophy and the Crisis of Modernity. Essays and Lectures in Modern Jewish Thought (Albany: State of New York University Press, 1997), 453; Jürgen Manemann, Carl Schmitt und die Politische Theologie (Münster: Aschendorff, 2002), 5-8.

87 Johann Baptist Metz, Memoria passionis (Santander: Sal Terrae, 2007), 236. 
responsabilidades políticas y económicas, y que sea lugar de asilo al extranjero. Estas políticas serían ya un «recuerdo de la palabra de Dios», pero nunca la era prometida ${ }^{88}$.

A modo de cierre caben algunas reflexiones críticas sobre esta propuesta. Un problema que debe notarse en esta comprensión del tiempo es su borramiento de las fronteras de las experiencias privadas y las comunitarias. Más que un borramiento, se trata de una identificación o inscripción de lo subjetivo en un significado trans-histórico que le trasciende. Aunque la experiencia comunitaria como meta es mucho más visible en Rosenzweig que en Levinas, permanece un problema este tipo de tensión-hacia para quienes no asuman dicho significado final. ¿Se trata, entonces, de una filosofía no-universalista, una filosofía solo válida para quienes asumen los compromisos simbólicos antes del uso de esta «nueva racionalidad»? Finalmente, una inquietante relación tiene que ver con un elemento esencial en Schmitt, el decisionismo. ¿̇No es acaso una decisión lo que lleva al sujeto comunicativo de Rosenzweig y al sujeto «obsesionado» de Levinas a entregarse al Otro? ¿No tiene el Otro una fuerza de autoridad que finalmente «hace la ley»? ${ }^{89}$. Schmitt ve en la cuestión de la decisión tanto el inicio de la experiencia de soberanía como la explicación del curso de acción pertinente en un momento en que la legitimación había perdido todo su valor por la traslación del Dios cartesiano y la estructura legal de la naturaleza al orden político ${ }^{90}$. Para ello recurre a una estructura medieval como la de Donoso Cortés. La pregunta que lógicamente aquí se impone aunque no sea el lugar para resolverla, es si Rosenzweig y Levinas, herederos de la Haskalá y fundamento del pensamiento dialógico contemporáneo, no terminan recayendo en una estructura de soberanía correspondiente a un pensamiento pre-moderno.

88 Emmanuel Levinas, A l'heure des nations (Paris: Les Éditions de Minuit, 1988), 113.

90 Carl Schmitt, Teología Política, 45. 


\section{Bibliografía}

Bensussan, Gérard. «Levinas et la question politique». Noesis [En ligne], 3 (2000). Consultada en junio 29, 2017. http://noesis. revues.org/9.

Casper, Bernhard. Das Dialogische Denken. Franz Rosenzweig, Ferdinand Ebner und Martin Buber, 2a edición. Freiburg/ München: Alber, 2002.

Casper, Bernhard. Pensar de cara a otro. Elementos del pensamiento de Emmanuel Levinas. Traducido por Diego Fonti. Córdoba: EDUCC, 2007.

Casper, Bernhard. El acontecimiento de orar. Líneas fundamentales de una hermenéutica del evento religioso. Traducido por Diego Fonti. Córdoba: Alción, 2011.

Caputo, John. «The poetics of the impossible and the Kingdom of God». En The Blackwell Companion to Postmodern Theology, editado por Graham Ward, 369-393. Malden-Oxford: Blackwell, 2005.

Feil, Ernst. Religio. Vierter Band: Die Geschichte eines neuzeitlichen Grundbegriffs im 18. und frühen 19. Jahrhunderts. Göttingen: Vandenhoeck \& Ruprecht, 2012.

Leconte, Mariana. Racionalidad y proximidad. Corrientes: Moglia, 2009.

Levinas, Emmanuel. Ethique et infini. Dialogues avec Philippe Nemo. Paris: Fayard et Radio-France, 1982.

Levinas, Emmanuel. De Dieu qui vient à l'idée. Paris: Vrin, 1982.

Levinas, Emmanuel. L ,au-delá du verset. Paris: Les Éditions du Minuit, 1982.

Levinas, Emmanuel. Autrement que savoir. Paris: Osiris, 1988.

Levinas, Emmanuel. A l'heure des nations. Paris: Les Éditions de Minuit, 1988. 
Levinas, Emmanuel. De otro modo que ser o más allá de la esencia. Traducido por Antonio Pintor-Ramos Salamanca: Sígueme, 1987.

Levinas, Emmanuel. Les imprévus de l'histoire. Paris: Fata Morgana, 1994.

Levinas, Emmanuel. Totalidad e infinito. Traducido por Daniel Guillot. Salamanca: Sígueme, 1995.

Levinas, Emmanuel. Altérité et transcendance. Paris: Fata Morgana, 1995.

Levinas, Emmanuel. Nouvelles lectures talmudiques, Paris: Les Éditions de Minuit, 1996.

Levinas, Emmanuel. Éthique comme philosophie première. Paris: Payot \& Rivages, 1998.

Levinas, Emmanuel. De la existencia al existente. Traducido por Patricio Peñalver. Madrid, Arena, 2000.

Manemann, Jürgen. Carl Schmitt und die Politische Theologie. Münster: Aschendorff, 2002.

Metz, Johann Baptist. Memoria passionis. Traducido por José Manuel Lozano. Santander: Sal Terrae, 2007.

Mosès, Stéphane. «Hegel beim Wort genommen». En Zeitgewinn: Messianisches Denken nach Franz Rosenzweig. Editado por Gottard Fuchs y Hans Hermann Henrix, 67-90. Frankfurt: Knecht, 1987.

Mosès, Stéphane. «Von der Zeit zur Ewigkeit». En Zeitgewinn: Messianisches Denken nach Franz Rosenzweig. Editado por Gottard Fuchs y Hans Hermann Henrix, 151-162. Frankfurt: Knecht, 1987.

Mosès, Stéphane. «From Rosenzweig to Levinas: Philosophy of War». En Political Theologies. Public Religions in a Post-Secular World. Editado por Hent de Vries y Lawrence E. Sullivan, 220-231. New York: Fordham University Press, 2006. 
Reyes Mate, Manuel. «Retrasar o acelerar el final». Nombres. Revista de Filosofía 21, Vol. xviI (2007): 17-33.

Rosenzweig, Franz. Hegel und der Staat. Erster Band: Lebenstationen. München und Berlin: Oldenbourg, 1920.

Rosenzweig, Franz. Hegel und der Staat. Zweiter Band: Weltepochen. München und Berlin: Oldenbourg, 1920.

Rosenzweig, Franz. Briefe und Tagebücher 1900-1918, Gesammelte Schriften 1, Band 1. Den Haag: Martinus Nijhoff, 1979.

Rosenzweig, Franz. Briefe und Tagebücher 1918-1929, Gesammelte Schriften 1, Band 2. Den Haag: Martinus Nijhoff, 1979.

Rosenzweig, Franz. Zweistromland. Kleinere Schriften zu Glauben und Denken, Gesammelte Schriften 3. Den Haag: Martinus Nijhoff, 1984.

Rosenzweig, Franz. El nuevo pensamiento. Traducido por Isidoro Reguera. Madrid: Visor, 1989.

Rosenzweig, Franz. La Estrella de la Redención. Traducido por Miguel García-Baró. Salamanca: Sígueme, 1997.

Schmitt, Carl. Teología Política. Traducido por Francisco Javier Conde y Jorge Navarro Pérez Madrid: Trotta, 2009.

Schmitt, Carl. Catolicismo romano y forma política. Traducido por Pedro Madrigal. Madrid: Tecnos, 2011.

Strauss, Leo. Jewish Philosophy and the Crisis of Modernity. Essays and Lectures in Modern Jewish Thought. Albany: State of New York University Press, 1997.

Voegelin, Eric. «The Political Religions». En Modernity Without Restraint, The Collected Works of Eric Voegelin Vol. 5, 19-74. Columbia-London: The University of Missouri Press, 2000. 